\title{
Retraction Note to: Research on the construction of intelligent management platform of garden landscape environment system based on remote sensing images
}

\author{
Lei Feng ${ }^{1}$. Jie Zhao ${ }^{1}$ \\ Published online: 27 December 2021 \\ (c) Saudi Society for Geosciences 2021
}

Retraction Note to: Arabian Journal of Geosciences (2021) 14: 1401 https://doi.org/10.1007/s12517-021-07739-3

The Editor-in-Chief and the Publisher have retracted this article because the content of this article is nonsensical. The peer review process was not carried out in accordance with the Publisher's peer review policy. Author Jie Zhao disagrees with this retraction. Author Lei Feng has not responded to correspondence regarding this retraction.

The original article can be found online at https://doi.org/10.1007/ s12517-021-07739-3.

Jie Zhao

zhaojie@hnjs.edu.cn

Lei Feng

zhaojie@ hnjs.edu.cn

1 Department of Architecture, Henan Technical College

of Construction, Zhengzhou 45000, Henan, China 